\title{
LC-MS/MS-based proteome profiling in Daphnia pulex and Daphnia longicephala: the Daphnia pulex genome database as a key for high throughput proteomics in Daphnia
}

\author{
Thomas Fröhlich ${ }^{\dagger 1}$, Georg J Arnold*1, Rainer Fritsch², Tobias Mayr ${ }^{2}$ and \\ Christian Laforsch*+2
}

\author{
Address: ${ }^{1}$ Laboratory for Functional Genome Analysis (LAFUGA), Gene Center, Ludwig-Maximilian University, 81377 Munich, Germany and \\ ${ }^{2}$ Department of Biology II and GeoBio-Center, Ludwig-Maximilians-University Munich, 82152 Martinsried, Germany \\ Email: Thomas Fröhlich - frohlich@lmb.uni-muenchen.de; Georg J Arnold* - arnold@lmb.uni-muenchen.de; \\ Rainer Fritsch - fritsch@zi.biologie.uni-muenchen.de; Tobias Mayr - mayr@zi.biologie.uni-muenchen.de; \\ Christian Laforsch* - laforsch@bio.lmu.de \\ * Corresponding authors †Equal contributors
}

Published: 21 April 2009

BMC Genomics 2009, 10:171 doi:10.1186/147|-2164-10-17|
Received: 14 March 2008

Accepted: 21 April 2009

This article is available from: http://www.biomedcentral.com/I47I-2/64/I0/I7I

(c) 2009 Fröhlich et al; licensee BioMed Central Ltd.

This is an Open Access article distributed under the terms of the Creative Commons Attribution License (http://creativecommons.org/licenses/by/2.0), which permits unrestricted use, distribution, and reproduction in any medium, provided the original work is properly cited.

\begin{abstract}
Background: Daphniids, commonly known as waterfleas, serve as important model systems for ecology, evolution and the environmental sciences. The sequencing and annotation of the Daphnia pulex genome both open future avenues of research on this model organism. As proteomics is not only essential to our understanding of cell function, and is also a powerful validation tool for predicted genes in genome annotation projects, a first proteomic dataset is presented in this article.

Results: A comprehensive set of 70I,274 peptide tandem-mass-spectra, derived from Daphnia pulex, was generated, which lead to the identification of 531 proteins. To measure the impact of the Daphnia pulex filtered models database for mass spectrometry based Daphnia protein identification, this result was compared with results obtained with the Swiss-Prot and the Drosophila melanogaster database. To further validate the utility of the Daphnia pulex database for research on other Daphnia species, additional 407,778 peptide tandem-mass-spectra, obtained from Daphnia longicephala, were generated and evaluated, leading to the identification of 317 proteins.

Conclusion: Peptides identified in our approach provide the first experimental evidence for the translation of a broad variety of predicted coding regions within the Daphnia genome. Furthermore it could be demonstrated that identification of Daphnia longicephala proteins using the Daphnia pulex protein database is feasible but shows a slightly reduced identification rate. Data provided in this article clearly demonstrates that the Daphnia genome database is the key for mass spectrometry based high throughput proteomics in Daphnia.
\end{abstract}

\section{Background}

During the last two decades, genome sequencing efforts are providing us with complete genome sequences from many organisms (for a summary refer to http:// www.ncbi.nlm.nih.gov/Genomes/). The generated sequence databases are fundamental tools used by 
researchers in almost every field of modern biology. In addition they provide the basis for powerful technologies to quantitatively analyze the gene expression profile on the mRNA-level using DNA microarrays $[1,2]$. However, it has to be considered that mRNA molecules are only intermediate products towards the production of functional proteins and that protein abundance is not necessarily reflected by the amount of the corresponding mRNA transcript $[3,4]$. The concentration of individual proteins at the cellular level or in biological fluids mainly depends on four completely different processes: (i) protein synthesis, (ii) protein processing, (iii) protein secretion and (iv) protein degradation. As a consequence, systematic quantitative predictions of protein populations are impossible to deduce from genomic or transcriptional data. Moreover, proteins frequently undergo post-translational modifications (PTMs) crucial for their function, activity, and stability and they often play major roles in regulatory networks [5]. Comprehensive datasets addressing the protein level, therefore, are indispensable for a functional and biochemical characterization of both cells and organisms. The field of high-throughput identification and quantification of proteins using systematic approaches is commonly referred to as proteomics. Recent developments in mass spectrometry have revolutionized the field and dramatically increased the sensitivity of protein identification compared to classical techniques like Edman sequencing. As a consequence, large proteome investigations have been established covering, e.g., human plasma [6], human brain [7] and human liver [8] as well as model organisms such as Caenorhabditis elegans [9] and Drosophila melanogaster [10].

This, in turn, has led to the realization that proteomics is not only essential to our understanding of cell function, but in addition is a validation tool for genes predicted in genome annotation projects. Recently published results demonstrate that peptide mass spectrometry complements gene annotation in Drosophila [10] and humans $[11,12]$.

Although a multitude of whole-genome sequencing projects ranging from microbial (e.g. [13]) to vertebrate genomes [14] have been initiated in the last decade, no complete genome sequence is available for crustaceans, a species-rich taxa with additional high economical impact.

Hence, the Daphnia Genomics Consortium (DGC; http:// daphnia.cgb.indiana.edu) was founded in 2003 to develop the waterflea Daphnia, a small planktonic crustacean, as a further model system in genomics, but with the added advantage of being able to interpret the results in the context of natural ecological challenges. Even though the ecology and ecotoxicology of Daphnia has been well studied, because they are a major link between limnetic primary production and higher trophic levels, less work has been done on the genetics of this organism. Nevertheless, their clonal reproduction, short generation times, and their transparent body also make them well suited for experimental molecular research.

In this special series of papers published in BMC journals, the first description of the Daphnia pulex draft genome sequence http://wFleaBase.org is described. Besides investigation on the DNA and mRNA level, the availability of the Daphnia genome sequence opens the door to investigate the proteome of this fascinating species. In this article we present the generation of a first data-set consisting of 701,274 peptide tandem-mass-spectra derived from Daphnia pulex. In order to demonstrate the impact of the Daphnia genome sequence on proteomics based studies we compared the number of identified proteins using the Daphnia protein database with the number of identifications obtained by searching against the Swiss-Prot and the Drosophila melanogaster protein database http://fly base.org/. To validate the utility of the Daphnia pulex genome for research on different Daphnia species, additional 407,778 peptide tandem-mass-spectra derived from Daphnia longicephala were generated and evaluated. In addition, the peptides identified in our approach provide the first experimental evidence for the translation of a broad variety of predicted coding regions within the Daphnia genome.

\section{Results}

\section{Sample preparation}

To generate protein lysates suitable for SDS gel electrophoresis, pools of about 300 waterfleas (Daphnia pulex and Daphnia longicelphala respectively) were homogenated. The protein concentration of the obtained lysates (2 mL) was $2.6 \mathrm{mg} / \mathrm{mL}$ for Daphnia pulex and $2.3 \mathrm{mg} / \mathrm{mL}$ for Daphnia longicephala corresponding to a total protein yield of $17 \mu \mathrm{g}$ and $15 \mu \mathrm{g}$ per Daphniid, respectively.

\section{SDS-gel pre-fractionation of Daphnia proteins}

$50 \mu \mathrm{g}$ of total protein from either Daphnia pulex or Daphnia longicephala, was separated by SDS-gel electrophoresis. To evaluate the quality of the electrophoretic separation, the gels were stained with Coomassie. An image of SDSgels derived from both Daphnia species is shown in Fig. 1. Both samples showed sharp distinct bands, indicating that the performed electrophoreses had good separation strengths. To generate 10 protein fractions of each sample, the corresponding gel lanes were cut into 10 pieces as outlined in Fig. 1. To get samples suitable for LC-MS/MS, each gel slice was subjected to the in-gel digestion procedure described in the Methods chapter. 

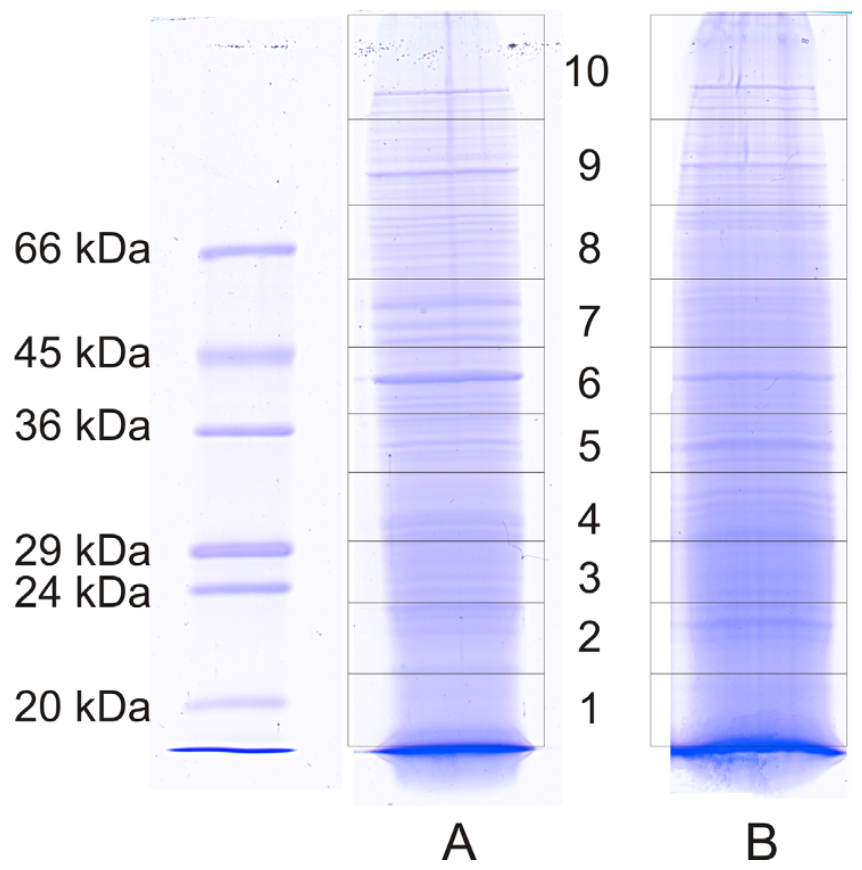

Figure I

Coomassie stained SDS-gels of Daphnia proteins. Scanned image of Coomassie stained SDS-gels. Panel A: 50 $\mu \mathrm{g}$ Daphnia pulex protein; Panel B: $50 \mu \mathrm{g}$ Daphnia longicephala protein. The rectangles indicate the 10 gel slices which were individually analyzed by LC-MS/MS.

\section{LC-MSIMS analysis of Daphnia pulex proteins}

For the qualitative analysis of the Daphnia pulex proteome, two samples were fractionized by SDS-gel electrophoresis (as described in the above paragraph) and subjected to LC-MS/MS analysis. Each of the 10 gel fractions was separated with one-dimensional reversed phase (RP) liquid chromatography (1D-LC) and a combination of strong cation-exchange (SCX) with RP chromatography (2D-LC) respectively. From the $1 \mathrm{D}-\mathrm{LC}-\mathrm{MS} / \mathrm{MS}$ runs 100,462 spectra could be collected and from the 2D-LC-MS/MS runs 600,812 spectra were acquired. All MS/MS spectra were searched against the non-redundant filtered models database of Daphnia v1.1 gene builds (July, 2007) http:// www.jgi.doe.gov/Daphnia/ and evaluated using the PeptideProphet software. Applying a false discovery rate of = $1 \%, 7973 \mathrm{MS} / \mathrm{MS}$ spectra could be assigned to peptides within the Daphnia database, of which 1654 were unique. The assignment of peptides to proteins using the ProteinProphet algorithm led to the identification of 186 proteins with the $1 \mathrm{D}-\mathrm{LC}-\mathrm{MS} / \mathrm{MS}$ approach and 524 proteins with the 2D-LC-MS/MS startegy (false positive discovery rate $=1 \%$ ). As shown in Fig. 2, all except seven proteins identified in the 1D-LC approach could be found in the 2D-LC-MS/MS dataset as well. Further analysis of the data revealed that a significant fraction of proteins could be identified in more than one gel slice, as summarized in

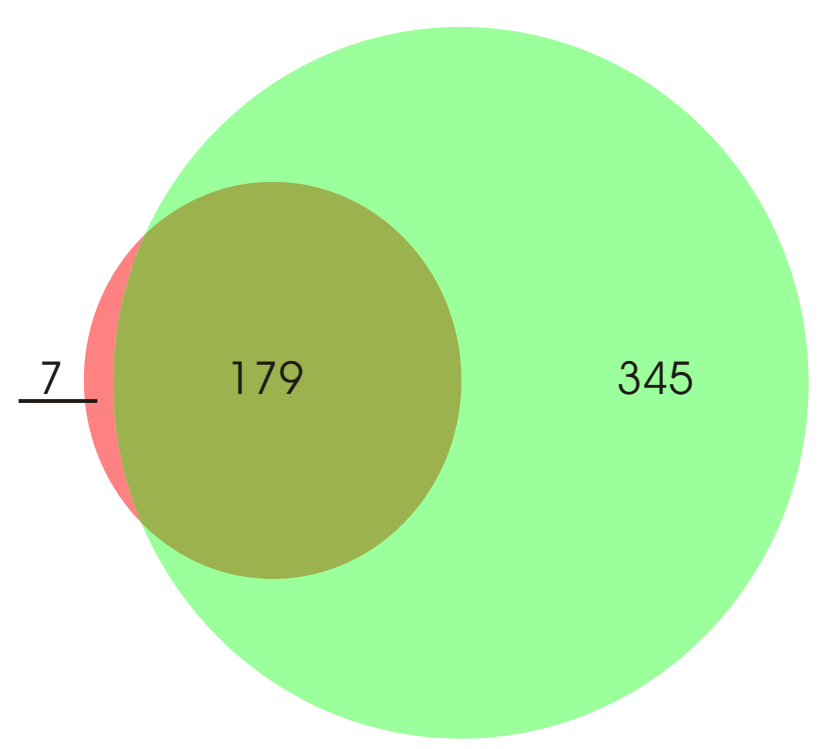

\section{Proteins identified by 1D-LC}

\section{Proteins identified by 2D-LC}

\section{Figure 2}

Proportional Venn diagram of protein overlap. Proportional Venn diagram demonstrating the degree of overlap of proteins identified by ID-LC-MS/MS and 2D-LC-MS/MS.

Fig. 3. The overall list of identified proteins and peptides is available as additional file 1.

\section{Ontology analysis of the identified proteins}

To analyze the ontology of the identified Daphnia pulex proteins the entries of the filtered models database were BLASTp-searched http://www.ncbi.nlm.nih.gov/BLAST/ in the Swiss-Prot database http://www.expasy.ch[15]. We chose the Swiss-Prot database because of its high level of annotation, including entries about protein function, posttranslational modifications as well as a direct link to the Gene Ontology (GO) databases [16]. From the 531 sequences derived from the filtered models database, 499 homologue (E-values $<0.01$ ) protein sequences could be found. The corresponding protein Swiss-Prot IDs were subjected to ontology analysis using the PANDORA server http://www.pandora.cs.huji.ac.il/. The results of this ontology analysis are shown in Fig. 4. In the "cellular component" GO database only 139 proteins of the 499 proteins were listed. Their classification analysis revealed that the majority $(65 \%)$ are of intracellular origin and the fraction of the particularly interesting class of membrane proteins comprises 27\%. The "molecular function" GO revealed 350 proteins the majority of which were classified as proteins with catalytic activity. From these fractions 141 were enzymes from which 68 could be classified as 


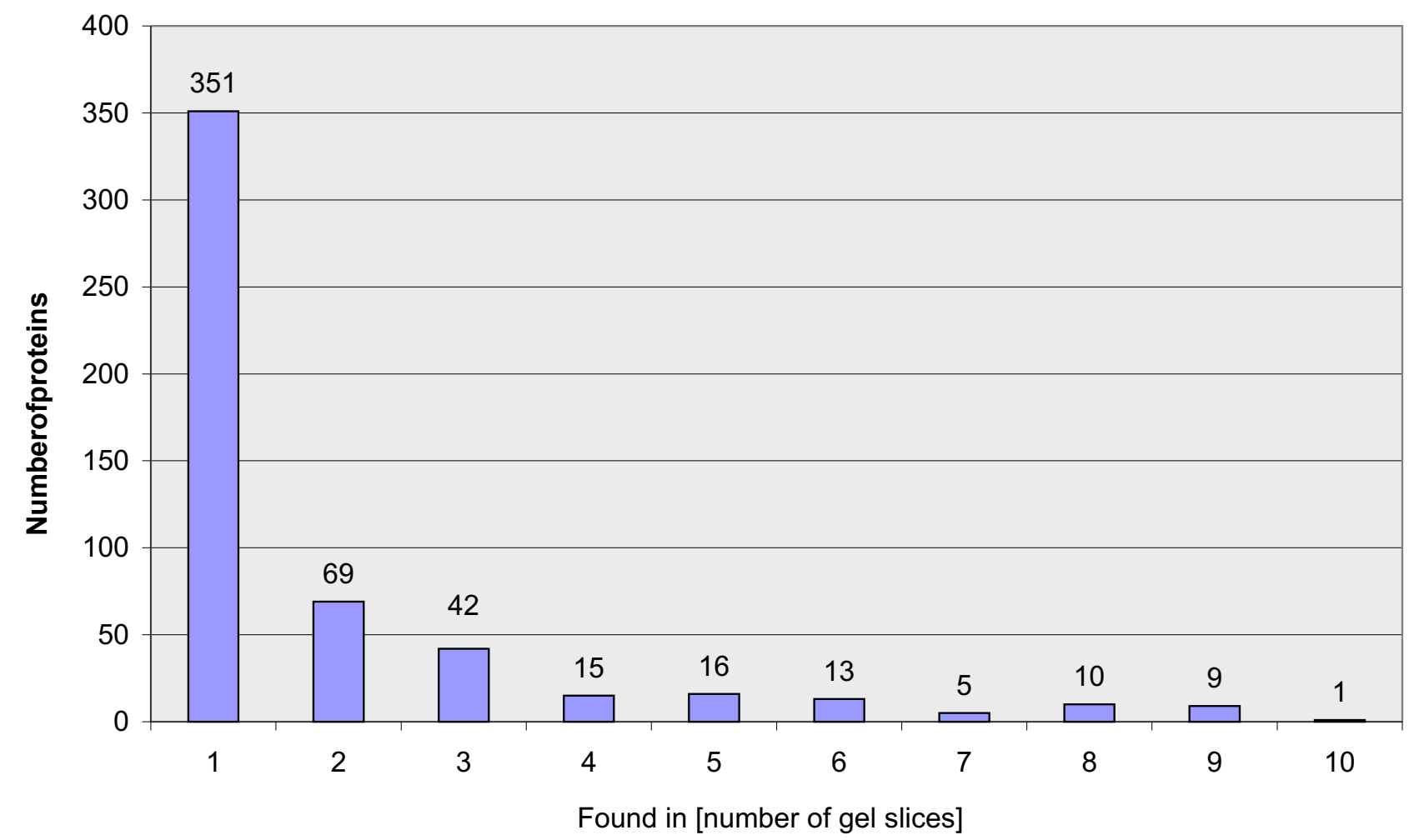

Figure 3

Identified proteins. Bar chart indicating the number of proteins identified in more than one gel slice. $X$ axis number of gel slices, $Y$ axis number of identified proteins by 2D-LC-MS/MS.

hydrolases, 33 as oxyreductases, 22 as transferases and 5 as lyases. 6 proteins could be classified as enzyme inhibitors. Using the "biological process" database 272 proteins could be classified from which 175 were associated with metabolism, 55 with cell growth and/or maintenance, 18 with cell communication, 15 with response to external stimulus and 9 with developmental processes.

\section{Searches of MSIMS data in the Swiss-Prot and Drosophila melanogaster protein database}

To investigate the benefit of the Daphnia pulex filtered models database on the MS based identification of Daphnia proteins, cross-species identification, as suggested by several authors $[17,18]$, was performed using the Metazoa subset of the Swiss-Prot database (Release 54.2, 78,385 entries) and the Drosophila melanogaster database from FlyBase (20,726 entries). Using the MS/MS spectra obtained with the 2D-LC-MS/MS runs of the Daphnia pulex sample, 71 Daphnia proteins could be identified with the Drosophila database and 92 with the Swiss-Prot database with a false-positive identification threshold of $=1 \%$.

\section{LC-MSIMS analysis of Daphnia longicephala proteins}

To determine the suitability of the non-redundant filtered models database of putative Daphnia pulex proteins for the MS-based identification of proteins from other Daphnia subgenera, a Daphnia longicephala protein lysate was generated. (A scanning electron micrograph from both, Daphnia pulex and Daphnia longicephala is shown in Fig. 5. For the protein identification exactly the same separation strategy as for D. pulex was used. Using this SDS-PAGE 2D-LC-MS/MS combination and the non-redundant filtered models database of putative Daphnia pulex proteins, we were able to identify 671 unique peptides (PeptideProphet, false discovery rate $=1 \%$ ) which could be assigned to 317 Daphnia longicephala proteins (ProteinProphet, false discovery rate $=1 \%$ ). As shown in Fig. 6, 86 of these proteins could exclusively be identified in Daphnia longicephala samples but not in Daphnia pulex samples.

\section{Discussion}

\section{General remarks}

For a comprehensive functional and biochemical characterization of organisms, an inventory of their proteins and protein modifications is a prerequisite. In the work presented here, we performed a liquid chromatography - 


\section{Cellular component}

\section{Biological process}
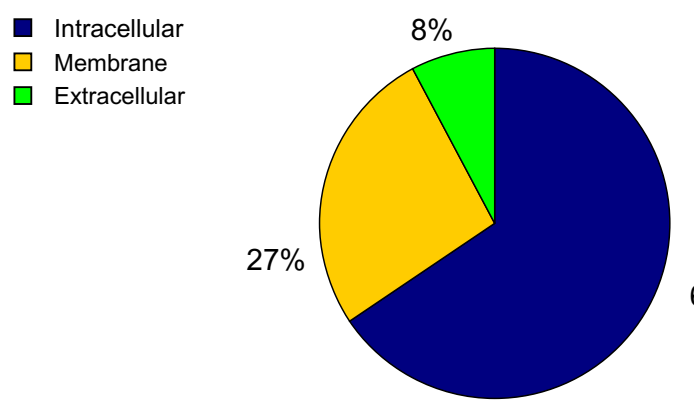

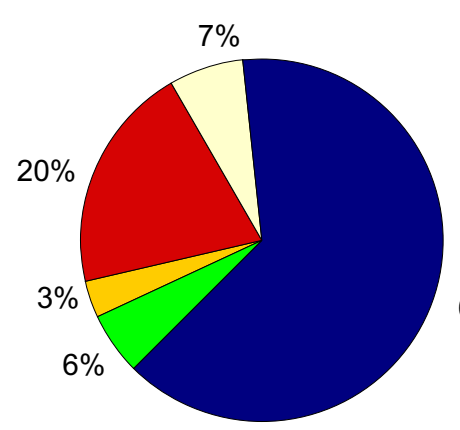

Development

Cell growth and/or maintenance

- Cell communication

- Metabolism

$\square$ Response to external stimulus

\section{Molecular function}

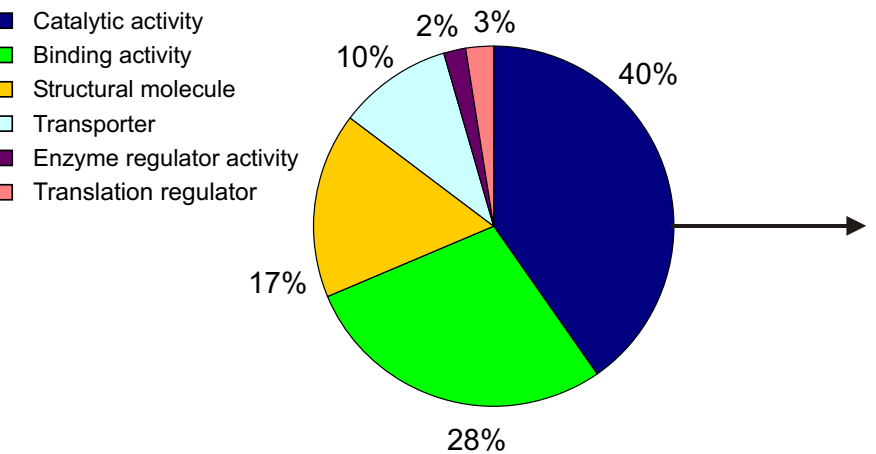

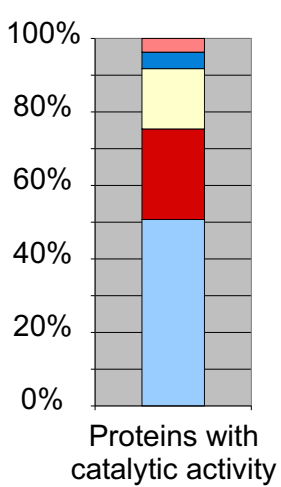

$\square$ Lyases

$\square$ Enzyme Inhibitors

$\square$ Transferases

$\square$ Oxyreductases

$\square$ Hydrolases

\section{Figure 4}

Ontology analysis. Ontology analysis of $50 \mathrm{I}$ identified Daphnia pulex proteins. The classification of the protein set was performed according to the gene ontology terms: "Cellular component", "Biological process" and "Molecular function".

mass spectrometry based qualitative proteome approach with the goal to generate a first protein catalogue of Daphnia pulex, the genome of which is presented in this special issue. To complement gene sequences, the generation of a broad dataset of tandem MS (MS/MS) spectra derived from Daphnia peptides is particularly interesting for two main reasons:

i) High throughput MS/MS protein identification is based on the comparison of experimentally acquired peptide MS/MS spectra with in silico generated theoretical spectra deduced from protein databases. With a large set of MS/ MS spectra it can be tested if the Daphnia filtered models protein database is suitable in its current form for proteomics approaches, which are mostly based on protein identification by MS/MS.

ii) The generation of MS/MS spectra derived from Daphnia peptides will lead to the creation of a catalogue of identified daphniid peptides. This will be one of the first data- sets giving experimental evidence for a variety of so far only predicted proteins. The Daphnia filtered models protein database in its current form consists of more than 30,000 entries. The corresponding genes were either found by EST sequencing, by homology searches, or $a b$ initio by gene prediction algorithms. However, for the broad majority of database entries, there is so far no experimental evidence that the corresponding genes are in fact translated and the resulting proteins persist in the organism.

\section{Experimental strategy}

Among all presently available proteomic techniques, the application of liquid chromatography (LC) as a separation tool combined with electrospray ionization (ESI) [19] tandem mass spectrometry (MS/MS) as an identification tool has the highest performance in terms of protein identifications per time unit. This technique is referred to as LC-MS/MS and has proven its efficiency in many studies [20-22]. Since eukaryotic proteomes consist of highly 


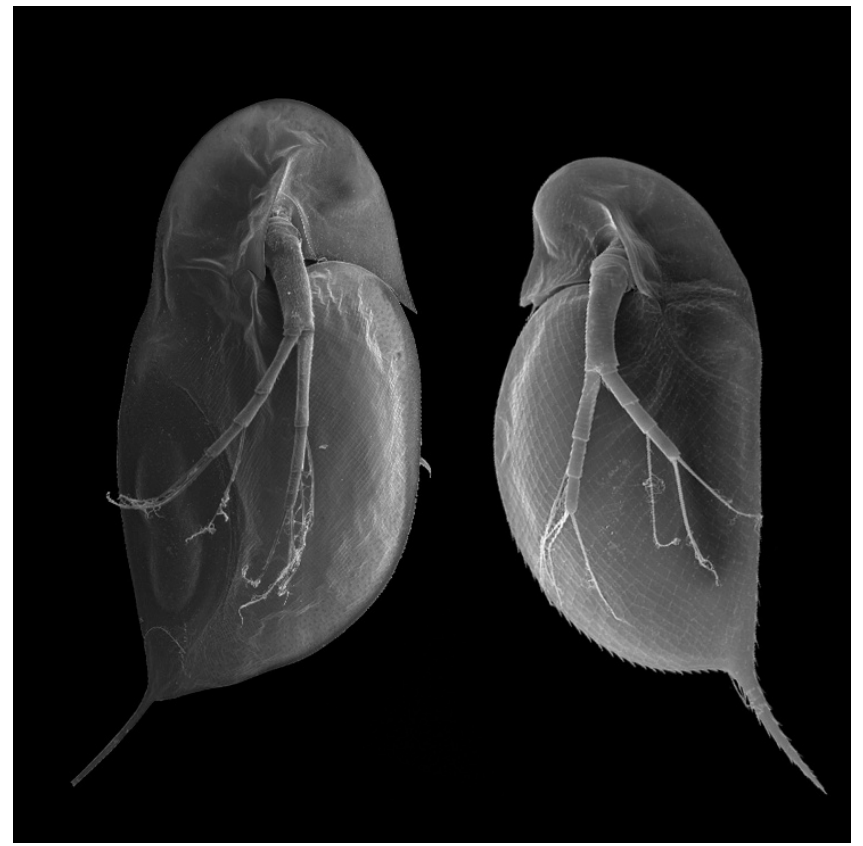

Figure 5

Daphnia images. Scanning electron micrograph from Daphnia longicephala (I) and Daphnia pulex (r).

complex mixtures, the reduction of complexity by prefractionation on the level of intact proteins prior to LCMS/MS analysis is mandatory. The number of identifications usually increases with the overall extent of prefractionation efforts. Because of its high separation strength we choose 1D-SDS-gel electrophoresis for pre-fractionation on the protein level. In this pilot study a number of 10 gel fractions were chosen. To determine the impact of two versus one chromatographic steps on the number of identified peptides, we compared the results obtained with one-dimensional reversed phase (RP) liquid chromatography (1D-LC) versus a combination of strong cation-exchange (SCX) with RP chromatography. The major advantage of the SCX - RP combination is the removal of salt ions from the SCX fractions in the RP step, which would otherwise interfere with the MS-analysis of peptide ions. For reasons of performance, we choose a fully automatic online setup, where SCX fractions are directly eluted onto a RP trap column. This RP trap column is then switched into the RP chromatography system to finally separate the peptides. The SCX flow through as well as 6 salt fractions from each of the 10 gel slices were captured and analyzed by LC-MS/MS; leading to a total number of 80 1D-LC-MS/MS runs (10 gel slices $\times 1$ RP-LC run +10 gel slices $\times 7 \mathrm{SCX}$ fractions $\times 1$ run $1 \mathrm{RP}-\mathrm{LC}$ run). From this workflow, 701,274 MS/MS spectra were obtained.

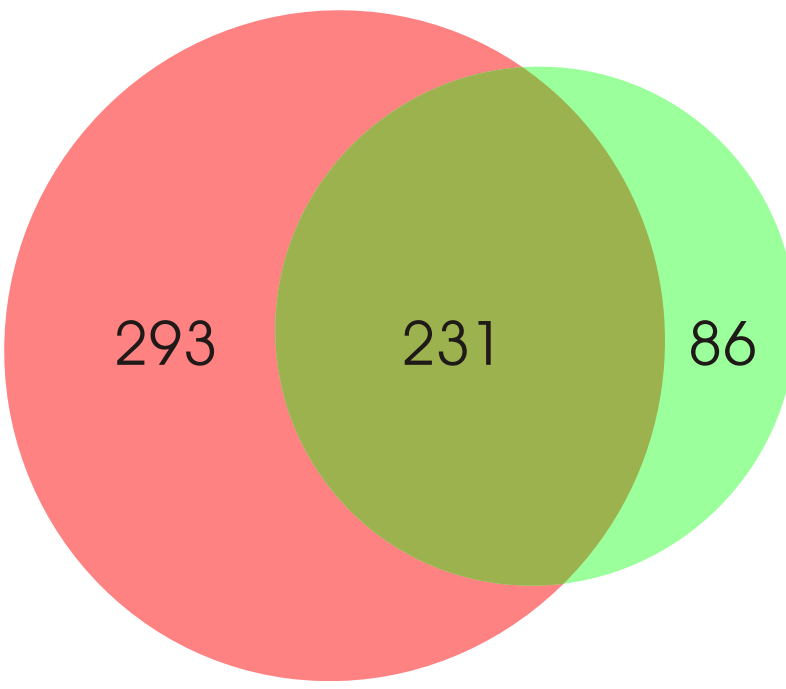

\section{Daphnia pulex}

\section{Daphnia longicephala}

\section{Figure 6}

Proportional Venn diagram of protein overlap. Proportional Venn diagram demonstrating the overlap of proteins identified from Daphnia pulex and Daphnia longicephala.

\section{Results obtained with LC-MSIMS}

Using SDS-PAGE combined with 1D-LC-MS/MS, we identified 186 entries whereas the SDS-PAGE - 2D-LC-MS combination led to the identification of 524 entries from the non-redundant filtered models database of putative Daphnia proteins demonstrating the benefit of a second chromatographic step. In total, we were able to identify 531 non-redundant filtered models database proteins of putative Daphnia pulex proteins. The overall list of identified proteins can be downloaded as additional file 1 .

Considering that the main goal of our experiments was to test the benefit of a dedicated Daphnia protein database for LC-MS/MS-based proteomics, this result is promising with respect to the straightforward design of this pilot study. As recently demonstrated by [10], an extensive prefractionation on the level of the biological sample (e.g. selection of different development stages), on the cellular, on the subcellular level as well as on the level of proteins and peptides had to be performed to get a catalogue of thousands of experimentally identified proteins from Drosophila. Our results clearly demonstrate that LC-MS/MS analysis combined with the usage of the Daphnia filtered models database is able to identify hundreds of Daphnia 
proteins with a high confidence level in a very efficient way. Therefore, this methodology combined with further pre-fractionation steps will lead to an increased analytical depth of the Daphnia proteome.

\section{Determination of false positive ratios}

The general strategy to identify peptides by high-throughput MS/MS experiments is a probability based comparison of experimental spectra with theoretical spectra calculated from protein databases deduced from DNA sequences. The software algorithms determine the closest match and a score indicating the reliability of the result. Although this identification strategy has proven its strength in many studies, cut-off values for the obtained scores must be chosen carefully to minimize false-positive identifications $[23,24]$. Unfortunately, there are no general rules for the confidence of given scores, because their reliability depends on the experimental setup as well as on the database used for the search. In our study, we applied the commonly used Mascot [25] search engine, returning a so called "ions score" for each peptide (for details see http://www.matrixscience.com/. However, special care must be taken when peptides spectra are used as evidence for the existence of corresponding proteins. Since a given peptide sequence can be present in multiple proteins, these shared peptides can lead to an overestimation of the number of identified proteins as well as to an under-estimation of the false discovery rate. An overview of this issue was given by Nesvizhskii et al. [26]. Therefore, to validate the Mascot search results we used the Trans-Proteomic Pipeline [27] downloadable from the Seattle Proteome Center http://tools.proteomecenter.org/ TPP.php. This software package includes PeptideProphet http://peptideprophet.sourceforge.net/ to compute probabilities for identified peptides [28] and ProteinProphet http://proteinprophet.sourceforge.net/ to address the issue of shared peptides and to calculate the probabilities of corresponding protein identifications [29]. To further confirm the false positive ratio given by the Trans-Pro- teomic pipeline we generated a so-called decoy version of the Daphnia pulex filtered models database consisting of random sequences with the same average amino acid composition. This decoy database was attached to the original database and then used to search our MS/MS spectra as proposed by Elias et al. [30]. Any protein hit derived from the decoy part of the combined database was regarded as false-positive identification. The number of four hits from the decoy part of the database is in accordance with the $1 \%$ false discovery rate calculated by the Trans-Proteomic Pipeline.

\section{Proteolytic activity}

The analysis of the data revealed that a significant fraction (34\%) of proteins could be identified in more than one gel slice, as summarized in Fig. 3. A heterogeneity of molecular masses is frequently observed in this kind of approaches [31,32]. and may be caused by posttranscriptional events such as alternative splicing, posttranslational modifications or proteolytic processing. While, inadequate separation strength of the gel can be excluded due to the presence of sharp distinct bands (see Fig. 1), proteolysis of these proteins prior to electrophoresis may contribute to this heterogeneity. Proteolysis can be caused by Daphnia proteases from the intestinal tract. The proteolytic activity of Daphnia magna gut protease was previously described $[33,34]$. In preliminary studies in which we performed 2D-gel electrophoresis of Daphnia magna and Daphnia longicephala lysates, we tried to eliminate this proteolytic activity with several commercially available protease inhibitor cocktails. The list of tested inhibitors, including the used concentrations, is shown in Table 1. However, the obtained spot patterns of all prepared 2Dgels still reflected significant protein degradation (Data not shown).

As the efficient inhibition of Daphnia proteases plays a crucial role in further quantitative proteome studies, we screened our catalogue of identified Daphnia proteins for

Table I: List of tested protease inhibitors

\begin{tabular}{lc}
\hline Protease Inhibitor & Concentration \\
\hline Protease Inhibitor Cocktail P8340 (Sigma Aldrich) & $2 \%$ \\
\hline Protease Inhibitor Cocktail P27I4 (Sigma Aldrich) & $3 \%$ \\
\hline Complete Protease Inhibitor Cocktail Tablets (Roche) & I tablet in $25 \mathrm{~mL}$ extraction buffer \\
\hline APMSF, TLCK, Chymostatin (Sigma Aldrich) & $79 \mu \mathrm{M} ; 160 \mu \mathrm{M} ; 83 \mu \mathrm{M}$ \\
\hline TLCK, TPCK (Sigma Aldrich) & $160 \mu \mathrm{M} ; 143 \mu \mathrm{M}$ \\
\hline Soybean Trypsin Inhibitor T 9003 (Sigma Aldrich) & $250 \mu \mathrm{M}$
\end{tabular}


proteases. In total, we have identified 19 different proteins out of the Daphnia database showing significant homology (BLAST E-value $<0.01$ ) to known proteases with exoas well as endopepdidase activity (Table 2). In the case of the Daphnia trypsin proteases identified, the masses of the detected peptides did not fit with the theoretical peptide masses of the porcine trypsin used for digestion of the samples. Hence, these peptides clearly originate from Daphnia proteins. The list of Daphnia proteases in Table 2 provides a basis for further sophisticated experiments, e.g. determination of cleavage specificities and screening for protease inhibitors.

\section{Usability of the D. pulex filtered models database for proteome research on other Daphnia subgenera}

In phylogenetics, the genus Daphnia is split into three subgenera, Daphnia, Hyalodaphnia and Ctenodaphnia. Sequence divergence between those subgenera indicates an origin in the Mesozoic [35]. Evolution under different environmental conditions such as UV radiation, salinity or predator regimes was certainly a key factor for diversification in this genus. To validate the utility of the Daphnia pulex genome sequence for proteome research on differing Daphnia species, we generated LC-MS/MS data of D. longicephala samples. D. longicephala was chosen due to the fact that it belongs to the taxon of Ctenodaphnia, in contrast to $D$. pulex which is grouped in the subgenus Daphnia. Moreover, $D$. longicephala is one of the most prominent examples for morphological plasticity [36] and provides an ideal model organism for future work on the genetic basis of the phenomenon of phenotypic plasticity.

For the proteome analysis of $D$. longicephala, identical amounts of total protein and the same 2D-LC-MS/MS strategy outlined for $D$. pulex was used. We were able to identify 317 proteins from the non-redundant filtered models database of putative Daphnia pulex proteins. The difference in number of identified proteins in $D$. pulex (524 in 2D-LC-MS/MS) may well mirror the genetic divergence between both Daphnia subgenera. This finding reflects the fact that even a single amino acid exchange in a given peptide mostly impairs its automatic identification by MS/MS search algorithms. Nevertheless, the number of identifications obtained from $D$. longicephala samples demonstrates the suitability of the D. pulex filtered models database for proteome investigations with other Daphnia subgenera.

Another finding is that 86 proteins were exclusively found in the Daphnia longicepha samples as illustrated in Fig. 6. This result might reflect different concentrations of a given protein in lysates of D. pulex and D. longicephala, e.g. through different metabolic activity and/or differences in their cellular assembly. On the other hand, this result may be due to undersampling, i.e., in highly complex samples, the number of co-eluting peptides exceeds the number of MS/MS spectra which can be acquired by the instrument. Therefore in individual LC-MS/MS runs, different lowintensity peptides may be selected for MS/MS analysis by the instrument software. The overall list of identified proteins can be downloaded as additional file 2 .

\section{The impact of the D. pulex filtered models database for proteome research of Daphniids}

Although several genome projects on crustaceans are in progress, only expressed sequence tag (EST) libraries (e.g. [37]) or the sequence of the mitochondrial genome [38] are available in other crustacean species. In cases where only few protein sequences are known, it is a common strategy to search MS/MS-data against databases of the most related species in order to identify identical peptides within the homologous proteins.

To estimate the impact of the D. pulex filtered models database for high-throughput proteomics of Daphniids, we compared the results obtained with the Daphnia database with the results obtained by searching our MS/MS dataset against two additional databases: As a species specific database we selected the Drosophila melanogaster database from FlyBase [39] (Release 5.2; http://flybase.org/) consisting of 20,726 protein sequences. We chose this species because $D$. melanogaster, belongs to the taxon of Hexapoda (Insecta and relatives) and is the closest relative of Daphnia pulex with a characterized complete genome sequence [40]. Both arthropod species belong to a group called Pancrustacea, although monophyly of this group is still discussed [41].

The Pancrustacean hypothesis, which is supported by molecular analysis (e.g. [42]), queries that Myriapoda are the closest relatives to Hexapoda but renders crustaceans and hexapods as sister taxa. Given that the latter have likely diverged 550 to 650 million years ago [43] and have evolved in completely different habitats - crustaceans predominantly in aquatic, insects in terrestrial environments - it is expected that protein expression should reflect these evolutionary challenges. Even though some crustacean gene families, such as genes responsible for embryonic development are shared with Hexapoda [44], several Daphnia genes show no sequence similarity to other arthropods [45]. Therefore, gene transcripts different from those of D. melanogaster might reflect adaptations to aquatic habitats such as chemoreception, oxygen uptake or osmoregulation.

As a protein database of a broad variety of species we chose the Metazoa subset of the Swiss-Prot database (Release 54.2, 78,385 entries) providing a minimum of redundancy. To facilitate a comparison of the results obtained with the different databases, searches of MS/MS 
Table 2: List of identified Daphnia proteins homologue to proteins with known exo- or endopeptidase activity

\begin{tabular}{|c|c|c|c|c|}
\hline Dappu Protein ID & $\begin{array}{c}\text { Homolgue to } \\
\text { [Swiss-Prot Accession] }\end{array}$ & E-Value & Protein name & Activity \\
\hline 302098 & $\underline{P 13676}$ & $9 \mathrm{E}-109$ & $\begin{array}{l}\text { Acylamino-acid-releasing enzyme (EC 3.4.19.I) } \\
\text { (Acyl-peptide hydrolase) (APH) (Acylaminoacyl- } \\
\text { peptidase) }\end{array}$ & $\begin{array}{l}\text { acylaminoacyl-peptidase } \\
\text { activity }\end{array}$ \\
\hline 203795 & $\underline{P I 5 \mid 45}$ & $7 E-155$ & $\begin{array}{l}\text { Aminopeptidase N (EC 3.4.II.2) (pAPN) (Alanyl } \\
\text { aminopeptidase) (Microsomal aminopeptidase) } \\
\text { (Aminopeptidase M) (CDI3) (gp /30) }\end{array}$ & Aminopeptidase activity \\
\hline 301437 & Q27245 & $2 \mathrm{E}-103$ & $\begin{array}{l}\text { Putative aminopeptidase W07G4.4 in } \\
\text { chromosome V (EC 3.4.II.-) }\end{array}$ & aminopeptidase activity \\
\hline 307838 & Q1075I & 0.0 & $\begin{array}{l}\text { Angiotensin-converting enzyme (EC 3.4.I5.I) } \\
\text { (Dipeptidyl carboxypeptidase I) (Kininase II) } \\
\text { (Fragment) }\end{array}$ & carboxypeptidase activity \\
\hline 195011 & P04069 & IE-90 & Carboxypeptidase B (EC 3.4.17.2) & carboxypeptidase activity \\
\hline 300872 & Q95029 & $3 E-123$ & $\begin{array}{l}\text { Cathepsin L precursor } \\
\text { (EC 3.4.22.I5) (Cysteine proteinase I) }\end{array}$ & $\begin{array}{l}\text { cysteine-type endopeptidase } \\
\text { activity }\end{array}$ \\
\hline 230618 & Q86GF7 & IE-36 & Crustapain & $\begin{array}{l}\text { cysteine-type endopeptidase } \\
\text { activity }\end{array}$ \\
\hline 126867 & $\underline{P I 2955}$ & $5 E-166$ & $\begin{array}{l}\text { Xaa-Pro dipeptidase (EC 3.4.13.9) (X-Pro } \\
\text { dipeptidase) (Proline dipeptidase) (Prolidase) } \\
\text { (Imidodipeptidase) }\end{array}$ & $\begin{array}{l}\text { metallocarboxypeptidase } D \\
\text { activity }\end{array}$ \\
\hline 201234 & $\underline{\mathrm{O} 80 \mathrm{~W} 54}$ & $3 \mathrm{E}-135$ & Farnesylated-proteins converting enzyme-I & $\begin{array}{l}\text { metalloendopeptidase } \\
\text { activity }\end{array}$ \\
\hline 200339 & $\underline{\mathrm{P} 23004}$ & $2 \mathrm{E}-66$ & $\begin{array}{l}\text { Ubiquinol-cytochrome } C \text { reductase complex } \\
\text { core protein } 2 \text {, mitochondrial precursor (EC } \\
\text { I.10.2.2) (Complex III subunit II) }\end{array}$ & $\begin{array}{l}\text { metalloendopeptidase } \\
\text { activity }\end{array}$ \\
\hline 200882 & $\underline{016796}$ & $3 E-14 \mid$ & Neprilysin-2 & $\begin{array}{l}\text { Probable cell surface } \\
\text { protease }\end{array}$ \\
\hline 231027 & $\underline{\mathrm{P} 00771}$ & $2 \mathrm{E}-62$ & $\begin{array}{l}\text { Brachyurin } \\
\text { (EC 3.4.21.32) (Collagenolytic protease) }\end{array}$ & $\begin{array}{l}\text { serine-type endopeptidase } \\
\text { activity }\end{array}$ \\
\hline 230885 & $\underline{\mathrm{P} 00765}$ & $\mathrm{IE}-52$ & Trypsin I (EC 3.4.2I.4) & $\begin{array}{l}\text { serine-type endopeptidase } \\
\text { activity }\end{array}$ \\
\hline 26258 & Q0087I & $3 \mathrm{E}-52$ & Chymotrypsin $\mathrm{BI}$ precursor (EC 3.4.2I.I) & $\begin{array}{l}\text { serine-type endopeptidase } \\
\text { activity }\end{array}$ \\
\hline 230174 & $\underline{\mathrm{P} 36178}$ & $3 \mathrm{E}-49$ & Chymotrypsin Bll precursor (EC 3.4.21.I) & $\begin{array}{l}\text { serine-type endopeptidase } \\
\text { activity }\end{array}$ \\
\hline 231152 & $\underline{\mathrm{P} 49275}$ & $9 \mathrm{E}-36$ & $\begin{array}{l}\text { Mite allergen Der } \mathrm{f} 3 \text { precursor (EC 3.4.2I.-) } \\
\text { (Der f III) }\end{array}$ & $\begin{array}{l}\text { serine-type endopeptidase } \\
\text { activity }\end{array}$ \\
\hline 231560 & $\underline{\mathrm{P} 048 \mid 4}$ & $3 \mathrm{E}-2 \mathrm{I}$ & Trypsin alpha precursor (EC 3.4.21.4) & $\begin{array}{l}\text { serine-type endopeptidase } \\
\text { activity }\end{array}$ \\
\hline $307 \mid 38$ & $\underline{P 97321}$ & $3 \mathrm{E}-119$ & $\begin{array}{l}\text { Seprase (EC 3.4.2I.-) (Fibroblast activation } \\
\text { protein alpha) } \\
\text { (Integral membrane serine protease) }\end{array}$ & $\begin{array}{l}\text { serine-type endopeptidase } \\
\text { activity; } \\
\text { exopeptidase activity }\end{array}$ \\
\hline 303911 & Q9DIA2 & $2 \mathrm{E}-178$ & $\begin{array}{l}\text { Cytosolic non-specific dipeptidase (CNDP } \\
\text { dipeptidase 2) } \\
\text { (Glutamate carboxypeptidase-like protein I) }\end{array}$ & Metallopeptidase activity \\
\hline
\end{tabular}


spectra were performed using exactly the same parameters. Setting a false-positive identification threshold of $1 \%$, only 71 Daphnia proteins matched to the Drosophila database and 92 to the Swiss-Prot database. This finding clearly demonstrates that the $D$. pulex filtered models database in its current form increases dramatically the number of MS-based identifications and represents an indispensable tool for high-throughput proteome experiments in daphniids. However, many proteins may still be missing in the database. Therefore, yet unassigned spectra in our data set can help to find undisclosed coding regions within the Daphnia genome. Suitable algorithms comprise searching against the entire Daphnia genome sequence or de-novo sequencing - MS BLAST approaches as described by Shevchenko et al. [46]. Finally, the database supports detailed 2D gel analyses to quantify and identify proteins. The application of the latter technique allows the determination of isolelectric points and molecular weights of the proteins and enables the detection of protein isoforms by comparison of experimentally determined IPs with theoretical IPs from database analysis.

\section{Conclusion}

Given that Daphnia is an important model organism, for instance to test for deleterious effects of pollutants or environmental changes, the implementation of state of the art techniques in molecular biology such as LC-MS/MS is an auspicious opportunity to unravel mechanisms triggering those critical environmental issues.

Our study is the first applying a LC-MS/MS based proteomic approach in Daphnia that reflects the utility of the Daphnia genome database for molecular works on this multifaceted model organism in several fields of biological research. Since a variety of Daphnia species are used for different scientific approaches, for instance to elucidate the phenomenon of phenotypic plasticity in daphniids [47] at least 20 species have been investigated intensively, it is essential to know the reliability of the Daphnia pulex genome sequence for studies on other species. We give experimental evidence for the translation of a broad variety of predicted coding regions within the Daphnia genome by using high throughput MS/MS protein identification in two Daphnia species. Our data demonstrates the applicability of proteomics research in $D$. pulex as well as in other Daphnia species. This will stimulate work on hypothetical functions for yet unclassified proteins followed by functional experiments in this new model organism. Moreover, proteomics techniques allow to identify proteins linked to biological phenomena such as induced predator defenses, host parasite-interactions or stress responses to toxic substances.

\section{Methods \\ Daphnia cultures}

We used a laboratory-cultured clonal line of Daphnia pulex and Daphnia longicephala for our experiments. The Daphnia pulex clone "The Chosen One" picked by the Daphnia Genomics Consortium for the sequencing project was isolated from an ephemeral pond in Oregon (USA) whereas Daphnia longicephala was isolated from Lara Pond (Australia).

Age-synchronized cohorts of both Daphnia species were grown prior to the experiments by collecting mothers with freshly deposited eggs. We cultured the latter in $30 \mathrm{~L}$ plastic buckets in the laboratory under constant conditions in a temperature-controlled room at $20^{\circ} \mathrm{C} \pm 0.5$. Fluorescent light was used to simulate a day-night rhythm (16 h day: $8 \mathrm{~h}$ night). The daphnids were fed daily with Scenedesmus obliquus at a concentration of $1.5 \mathrm{mg} \mathrm{C} \mathrm{L-1}$ to avoid food limitation. A synthetic medium based on ultra-pure water, trace-elements and phosphate buffer, was changed weekly [48]. 300 randomly chosen adult daphnids were collected prior to proteome analysis.

\section{Sample preparation}

The medium containing the daphnids was filtered through a fine sieve (mesh aperture $125 \mu \mathrm{m}$ ) and immediately grounded in a pre-cooled ceramic mortar containing liquid nitrogen. For lysis, the following chemicals were added to final concentrations of $8 \mathrm{M}$ urea, $4 \%$ CHAPS, $40 \mathrm{mM}$ Tris, $65 \mathrm{mM}$ DTE. If pre-fractionation by SDS PAGE was performed, $400 \mu \mathrm{M}$ TLCK and $400 \mu \mathrm{M}$ TCPK protease inhibitors were added.

\section{SDS PAGE}

Prior to SDS-PAGE the samples were mixed with $5 \times$ sample buffer. SDS-electrophoresis (overall gel size $7 \mathrm{~cm} \mathrm{(L)} \times$ $8.5 \mathrm{~cm}(\mathrm{~W}) \times 0.75 \mathrm{~mm}$ ) was performed using a $1.5 \mathrm{~cm} 4 \%$ stacking gel (0.5 M Tris- $\mathrm{HCl}$ pH $6.8,4 \%$ acrylamide-/bisacrylamide (37.5/1), 0.1\% w/v SDS, $0.05 \% \mathrm{w} / \mathrm{v}$ APS, $0.1 \%$ $\mathrm{v} / \mathrm{v}$ TEMED) and a $12 \%$ separation gel $(1.5 \mathrm{M}$ Tris- $\mathrm{HCl} \mathrm{pH}$ $8.8,12 \%$ acrylamide/bisacrylamide (37.5/1), $0.1 \% \mathrm{w} / \mathrm{v}$ SDS, $0.05 \% \mathrm{w} / \mathrm{v}$ APS, $0.05 \% \mathrm{v} / \mathrm{v}$ TEMED) with a mini-ProteanTM II device (Bio-Rad, Hercules, USA). Gels were run for $15 \mathrm{~min}$ at a constant voltage of $100 \mathrm{~V}$ and for additional $60 \mathrm{~min}$ at $200 \mathrm{~V}$ in SDS running buffer $(25 \mathrm{mM}$ Tris, $192 \mathrm{mM}$ glycin, $0.1 \% \mathrm{w} / \mathrm{v}$ SDS). The gels were stained overnight $(50 \% \mathrm{v} / \mathrm{v}$ methanol, $0.05 \% \mathrm{w} / \mathrm{v}$ Coomassie brilliant blue R-250, 10\% v/v acetic acid) and destained for at least $8 \mathrm{~h}(5 \%(\mathrm{v} / \mathrm{v})$ Methanol with 7\% (v/v) acetic acid).

\section{Gel slicing and tryptic in-gel digest}

Prior to gel slicing, the gels were washed twice in water. After washing, each gel line was cut into 10 slices using a scalpel. Each slice was transferred in a $1.5 \mathrm{~mL}$ reaction tube and equilibrated twice with $50 \mathrm{mM} \mathrm{NH}_{4} \mathrm{HCO}_{3}$ for 10 
min. To reduce and block the cystein residues, the gel slices were incubated for $45 \mathrm{~min}$ in $50 \mathrm{mM} \mathrm{NH}_{4} \mathrm{HCO}_{3} / 10$ $\mathrm{mM}$ DTE at $65^{\circ} \mathrm{C}$, followed by a $30 \mathrm{~min}$ incubation step in $50 \mathrm{mM} \mathrm{NH}_{4} \mathrm{HCO}_{3}$ with $55 \mathrm{mM}$ iodacetamide. Prior to digestion, gel pieces were washed twice for $15 \mathrm{~min}$ in 50 $\mathrm{mM} \mathrm{NH} \mathrm{HCO}_{3}$ and minced with a pipette tip. Tryptic hydrolysis was performed overnight at $37^{\circ} \mathrm{C}$ in $30 \mu \mathrm{L} 50$ $\mathrm{mM} \mathrm{NH}_{4} \mathrm{HCO}_{3}$ with $1 \mu \mathrm{g}$ porcine trypsin (Promega, Madison, USA) per gel slice. The supernatant was collected and preserved. The peptides were further extracted with $50 \mu \mathrm{L}$ $50 \mathrm{mM} \mathrm{NH}_{4} \mathrm{HCO}_{3}$ and a subsequent treatment using 50 $\mu \mathrm{L} 80 \%$ ACN. Both extraction steps were performed for 5 min under sonification (Sonorex RK100, Bandelin, Berlin, Germany). The ACN supernatant and the $\mathrm{NH}_{4} \mathrm{HCO}_{3}$ fractions were combined and concentrated to a volume of 10 $\mu \mathrm{L}$ using a SpeedVac concentrator (Bachover, Vacuum Concentrator). Prior to 2D-LC-MS/MS analysis the peptide were desalted using Pepclean C-18 spin columns (Pierce) as described by the manufacturer.

\section{ID-LC separation}

The 1D-nano-LC separation was performed on a multidimensional liquid chromatography system (Ettan MDLC, GE Healthcare). Peptides were loaded on a RP trap column with a flow-rate of $6 \mu \mathrm{L}$ per min (Loading buffer: 0.1\% formic acid; Trap column: C18 PepMap 100, $5 \mu \mathrm{m}$ bead size, $300 \mu \mathrm{m}$ i.d., $5 \mathrm{~mm}$ length, LC Packings) and subsequently separated with an analytical column (C18 PepMap 100, $3 \mu \mathrm{m}$ bead size, $75 \mu \mathrm{m}$ i.d.; $15 \mathrm{~cm}$ length, LC Packings) with a 72 min linear gradient (A: $0.1 \%$ formic acid, B: $84 \% \mathrm{ACN}$ and $0.1 \%$ formic acid) at a flow rate of $260 \mathrm{~nL} / \mathrm{min}$.

\section{D-LC separation}

The 2D-nano-LC separation was performed on a multidimensional liquid chromatography system (Ettan MDLC, GE Healthcare). An online salt step configuration was chosen, in which $10 \mu \mathrm{g}$ of the desalted peptide mixture was injected onto a $50 \times 0.32 \mathrm{~mm}$ SCX column (BioBasic, Thermo Electron) and eluted at a flow rate of $6 \mu \mathrm{L} /$ min with 6 discrete salt plugs of increasing salt concentration $\left(10,25,50,100,500\right.$ and $800 \mathrm{mM} \mathrm{NH}_{4} \mathrm{Cl}$ in $0.1 \%$ formic acid and 5\% ACN). The eluted peptides were bound on a RP trap column (C18 PepMap 100, 5 Hm, 300 $\mu \mathrm{m}$ i.d. $5 \mathrm{~mm}$, LC Packings) and subsequently separated on the second-dimension RP column (C18 PepMap 100, $3 \mu \mathrm{m}, 75 \mu \mathrm{m}$ i.d. $15 \mathrm{~cm}$, LC Packings) with a 72 min linear gradient (A: $0.1 \%$ formic acid, B: $84 \% \mathrm{ACN}$ and $0.1 \%$ formic acid) at a flow rate of $260 \mathrm{~nL} / \mathrm{min}$.

\section{Mass spectrometry}

Mass spectrometry was performed on a linear ion trap mass spectrometer (Thermo LTQ, Thermo Electron) online coupled to a nano-LC system. For electrospray ionization a distal coated SilicaTip (FS-360-50-15-D-20) and a needle voltage of $1.4 \mathrm{kV}$ was used. The MS method consisted of a cycle combining one full MS scan (Mass range: $300-2000 \mathrm{~m} / \mathrm{z}$ ) with three data dependant MS/MS events (35\% collision energy). The dynamic exclusion was set to $30 \mathrm{~s}$.

\section{Database search and data analysis}

The MS/MS data were searched with Mascot Version: 2.1.03 (Matrix Science, Boston, USA) using the following parameters: i) Enzyme: Trypsin, ii) Fixed Modification: Carbamidomethyl (C), iii) Variable modifications: Oxidation (M); iv) Peptide tol. 2 Da, v) MS/MS tol. 0.8 Da, vi) Peptide charge $1+, 2+$ and $3+$, vii) Instrument ESI-TRAP and viii) Allow up to 1 missed cleavages. Mascot results were further validated with the open source software "Trans-Proteomic Pipeline" (TPP) V3.5 freely available from the Seattle Proteome Center http://tools.proteome center.org/TPP.php. Therefore the Mascot DAT files were first converted to mzXML, merged and evaluated on the peptide level with the built-in PeptideProphet tool. To generate the list of identified proteins (false positive discovery rate of $=1 \%$ ) the ProteinProphet tool was used. Furthermore, randomized versions of the applied databases were appended to the original databases using the decoy perl script (Matrix Science, Boston, USA) downloadable at http://www.matrixscience.com/help/ decoy help.html. The number of false positive identifications (randomized sequences) using the Mascot/TPP combination and the corresponding probability thresholds was determined.

\section{Ontology analysis}

Protein entries from the Daphnia filtered models database v1.1 were BLASTp-searched http://www.ncbi.nlm.nih.gov /BLAST/ in the Swiss-Prot database http://www.expasy.ch. Homologue protein entries (E-values < 0.01) were subjected to ontology analysis using the PANDORA server http://www.pandora.cs.huji.ac.il/.

\section{Abbreviations}

1D: one-dimensional; 2D: two-dimensional; DGC: Daphnia Genomics Consortium; ESI: electrospray ionization; EST: expressed sequence tag; GO: gene ontology; LC: liquid chromatography; LC: liquid chromatography; MS/MS: tandem mass spectrometry; MS: mass spectrometry; PTMs: post-translational modifications; RP: reversed phase; SCX: strong cation-exchange.

\section{Authors' contributions}

TF participated in the design of the study, performed the LC-MS/MS experiments, data analysis as well as data interpretation and contributed to the writing of the manuscript. CL initiated and coordinated the study and participated in its design; supervised the biological part of the study; performed sample preparation; performed crit- 
ical reading and writing of the paper. $\mathrm{RF}$ and $\mathrm{TB}$ carried out Daphnia cultivation, preparation of samples for mass spectrometry and contributed to the bioinformatic processing of the data. GJA supervised the proteomic part of the work and contributed to project conception and manuscripts writing.

\section{Additional material}

\section{Additional File 1}

Identified Daphnia pulex proteins. Contains Daphnia pulex proteins, ProteinProphet error graph, a list of identified Daphnia pulex peptides and proteins with corresponding PeptideProphet, ProteinProphet and Mascot scores and results of BLAST searches.

Click here for file

[http://www.biomedcentral.com/content/supplementary/14712164-10-171-S1.xls]

\section{Additional File 2}

Identified Daphnia longicephala proteins. Contains Daphnia longicephala proteins, ProteinProphet error graph, a list of identified Daphnia longicephala peptides and proteins with corresponding PeptideProphet, ProteinProphet and Mascot scores and results of BLAST searches.

Click here for file

[http://www.biomedcentral.com/content/supplementary/14712164-10-171-S2.xls]

\section{Acknowledgements}

We thank Patrick Bolbrinker and Erik Dülsner for critical reading of the manuscript, Piers Napper for linguistic improvement and, Mechthild Kredler for helping with the Daphnia cultivation and sample preparation. Research work in our laboratory is granted by the "Deutsche Forschungsgemeinschaft", DFG research unit FOR 478 AR 362/I-4, DFG clinical research unit KFO I28 I-2, BMBF FUGATO project AZ 03।3388, DFG research unit FOR 585 AR 362/3-2. The sequencing and portions of the analyses were performed at the DOE Joint Genome Institute under the auspices of the U.S. Department of Energy's Office of Science, Biological and Environmental Research Program, and by the University of California, Lawrence Livermore National Laboratory under Contract No. W-7405Eng-48, Lawrence Berkeley National Laboratory under Contract No. DEAC02-05CHI I 23I, Los Alamos National Laboratory under Contract No. W-7405-ENG-36 and in collaboration with the Daphnia Genomics Consortium (DGC) http://daphnia.cgb.indiana.edu. Additional analyses were performed by wFleaBase, developed at the Genome Informatics Lab of Indiana University with support to Don Gilbert from the National Science Foundation and the National Institutes of Health. Coordination infrastructure for the DGC is provided by The Center for Genomics and Bioinformatics at Indiana University, which is supported in part by the METACyt Initiative of Indiana University, funded in part through a major grant from the Lilly Endowment, Inc. Our work benefits from, and contributes to the Daphnia Genomics Consortium.

\section{References}

I. Lockhart DJ, Winzeler EA: Genomics, gene expression and DNA arrays. Nature 2000, 405:827-836.

2. Schena M, Shalon D, Davis RW, Brown PO: Quantitative Monitoring of Gene-Expression Patterns with A ComplementaryDna Microarray. Science 1995, 270:467-470.
3. Anderson L, Seilhamer J: A comparison of selected mRNA and protein abundances in human liver. Electrophoresis 1997, 18:533-537.

4. Gygi SP, Rochon Y, Franza BR, Aebersold R: Correlation between protein and mRNA abundance in yeast. Mol Cell Biol 1999, 19:1720-1730.

5. Tekirian TL, Thomas SN, Yang A: Advancing signaling networks through proteomics. Expert Rev Proteomics 2007, 4:573-583.

6. Omenn GS, States DJ, Adamski M, Blackwell TW, Menon R, Hermjakob H, Apweiler R, Haab BB, Simpson RJ, Eddes JS, Kapp EA, Moritz RL, Chan DW, Rai AJ, Admon A, Aebersold R, Eng J, Hancock WS, Hefta SA, Meyer H, Paik YK, Yoo JS, Ping P, Pounds J, Adkins J, Qian $X$, Wang R, Wasinger V, Wu CY, Zhao X, Zeng R, Archakov A, Tsugita A, Beer I, Pandey A, Pisano M, Andrews P, Tammen H, Speicher DW, Hanash SM: Overview of the HUPO Plasma Proteome Project: results from the pilot phase with 35 collaborating laboratories and multiple analytical groups, generating a core dataset of $\mathbf{3 0 2 0}$ proteins and a publicly-available database. Proteomics 2005, 5:3226-3245.

7. Hamacher M, Apweiler R, Arnold G, Becker A, Bluggel M, Carrette $O$, Colvis C, Dunn MJ, Frohlich T, Fountoulakis M, van Hall A, Herberg F, Ji J, Kretzschmar H, Lewczuk P, Lubec G, Marcus K, Martens L, Palacios Bustamante N, Park YM, Pennington SR, Robben J, Stuhler K, Reidegeld KA, Riederer P, Rossier J, Sanchez JC, Schrader M, Stephan C, Tagle D, Thiele H, Wang J, Wiltfang J, Yoo JS, Zhang C, Klose J, Meyer HE: HUPO Brain Proteome Project: summary of the pilot phase and introduction of a comprehensive data reprocessing strategy. Proteomics 2006, 6:4890-4898.

8. He F: Human liver proteome project: plan, progress, and perspectives. Mol Cell Proteomics 2005, 4: I84I-I848.

9. Paik YK, Jeong SK, Lee EY, Jeong PY, Shim YH: C. elegans: an invaluable model organism for the proteomics studies of the cholesterol-mediated signaling pathway. Expert Rev Proteomics 2006, 3:439-453.

10. Brunner E, Ahrens CH, Mohanty S, Baetschmann H, Loevenich S, Potthast F, Deutsch EW, Panse C, de Lichtenberg U, Rinner O, Lee H, Pedrioli PG, Malmstrom J, Koehler K, Schrimpf S, Krijgsveld J, Kregenow F, Heck AJ, Hafen E, Schlapbach R, Aebersold R: A high-quality catalog of the Drosophila melanogaster proteome. Nat Biotechnol 2007, 25:576-583.

II. Fermin D, Allen BB, Blackwell TW, Menon R, Adamski M, Xu Y, Ulintz $P$, Omenn GS, States DJ: Novel gene and gene model detection using a whole genome open reading frame analysis in proteomics. Genome Biol 2006, 7:R35.

12. Tanner S, Shen Z, Ng J, Florea L, Guigo R, Briggs SP, Bafna V: Improving gene annotation using peptide mass spectrometry. Genome Res 2007, 17:231-239.

13. Cole ST, Brosch R, Parkhill J, Garnier T, Churcher C, Harris D, Gordon SV, Eiglmeier K, Gas S, Barry CEIII, Tekaia F, Badcock K, Basham D, Brown D, Chillingworth T, Connor R, Davies R, Devlin K, Feltwell T, Gentles S, Hamlin N, Holroyd S, Hornsby T, Jagels K, Krogh A, McLean J, Moule S, Murphy L, Oliver K, Osborne J, Quail MA, Rajandream MA, Rogers J, Rutter S, Seeger K, Skelton J, Squares R, Squares S, Sulston JE, Taylor K, Whitehead S, Barrell BG: Deciphering the biology of Mycobacterium tuberculosis from the complete genome sequence. Nature 1998, 393:537-544.

14. Lander ES, Linton LM, Birren B, Nusbaum C, Zody MC, Baldwin J, Devon K, Dewar K, Doyle M, FitzHugh W, Funke R, Gage D, Harris K, Heaford A, Howland J, Kann L, Lehoczky J, LeVine R, McEwan P, McKernan K, Meldrim J, Mesirov JP, Miranda C, Morris W, Naylor J, Raymond C, Rosetti M, Santos R, Sheridan A, Sougnez C, et al.: Initial sequencing and analysis of the human genome. Nature 200I, 409:860-92i.

15. Gasteiger E, Gattiker A, Hoogland C, Ivanyi I, Appel RD, Bairoch A: ExPASy: The proteomics server for in-depth protein knowledge and analysis. Nucleic Acids Res 2003, $31: 3784-3788$

16. The Gene Ontology (GO) project in 2006. Nucleic Acids Res 2006, 34:D322-D326.

17. Barrett J, Brophy PM, Hamilton JV: Analysing proteomic data. Int J Parasitol 2005, 35:543-553.

18. Biron DG, Brun C, Lefevre T, Lebarbenchon C, Loxdale HD, Chevenet F, Brizard JP, Thomas F: The pitfalls of proteomics experiments without the correct use of bioinformatics tools. Proteomics 2006, 6:5577-5596.

19. Mann M, Wilm M: Electrospray mass spectrometry for protein characterization. Trends Biochem Sci 1995, 20:219-224. 
20. Frohlich T, Arnold G]: Proteome research based on modern liquid chromatography-tandem mass spectrometry: separation, identification and quantification. J Neural Transm 2006, I I 3:973-994.

21. Ishihama Y: Proteomic LC-MS systems using nanoscale liquid chromatography with tandem mass spectrometry. J Chromatogr A 2005, I 067:73-83.

22. Shen $Y$, Smith RD: Advanced nanoscale separations and mass spectrometry for sensitive high-throughput proteomics. Expert Rev Proteomics 2005, 2:43 I-447.

23. Wilkins MR, Appel RD, Van Eyk JE, Chung MC, Gorg A, Hecker M, Huber LA, Langen $\mathrm{H}$, Link AJ, Paik YK, Patterson SD, Pennington SR, Rabilloud T, Simpson RJ, Weiss W, Dunn MJ: Guidelines for the next 10 years of proteomics. Proteomics 2006, 6:4-8.

24. Nesvizhskii Al, Vitek $O$, Aebersold $R$ : Analysis and validation of proteomic data generated by tandem mass spectrometry. Nat Methods 2007, 4:787-797.

25. Perkins DN, Pappin DJ, Creasy DM, Cottrell JS: Probability-based protein identification by searching sequence databases using mass spectrometry data. Electrophoresis 1999, 20:355 I-3567.

26. Nesvizhskii Al, Aebersold R: Interpretation of shotgun proteomic data: the protein inference problem. Mol Cell Proteomics 2005, 4: 1419-1440.

27. Keller A, Eng J, Zhang N, Li XJ, Aebersold R: A uniform proteomics MS/MS analysis platform utilizing open XML file formats. Mol Syst Biol 2005, I:.

28. Keller A, Nesvizhskii Al, Kolker E, Aebersold R: Empirical statistical model to estimate the accuracy of peptide identifications made by MS/MS and database search. Anal Chem 2002, 74:5383-5392.

29. Nesvizhskii Al, Keller A, Kolker E, Aebersold R: A statistical model for identifying proteins by tandem mass spectrometry. Anal Chem 2003, 75:4646-4658.

30. Elias JE, Haas W, Faherty BK, Gygi SP: Comparative evaluation of mass spectrometry platforms used in large-scale proteomics investigations. Nat Methods 2005, 2:667-675.

31. Ahmad QR, Nguyen DH, Wingerd MA, Church GM, Steffen MA: Molecular weight assessment of proteins in total proteome profiles using ID-PAGE and LC/MS/MS. Proteome Sci 2005, 3:6

32. Kwon KH, Park GW, Kim JY, Lee SK, Lee JH, Kim YH, Kim SY, Park YM, Yoo JS: Island clustering analysis for the comparison of the membrane and the soluble protein fractions of human brain proteome. Proteomics 2008, 8: I |49-I I6I.

33. Agrawal MK, Zitt A, Bagchi D, Weckesser J, Bagchi SN, von Elert E: Characterization of proteases in guts of Daphnia magna and their inhibition by Microcystis aeruginosa PCC 7806. Environ Toxicol 2005, 20:314-322.

34. von Elert E, Agrawal MK, Gebauer C, Jaensch H, Bauer U, Zitt A: Protease activity in gut of Daphnia magna: evidence for trypsin and chymotrypsin enzymes. Comp Biochem Physiol B Biochem Mol Biol 2004, I 37:287-296.

35. Colbourne JK, Hebert PD: The systematics of North American Daphnia (Crustacea: Anomopoda): a molecular phylogenetic approach. Philos Trans R Soc Lond B Biol Sci 1996, 35 I:349-360.

36. Tollrian R, Dodson SI: Inducible defenses in Cladocera: constraints, costs and multipredator environments. In The Ecology and Evolution of inducible Defenses Edited by: Tollrian R, Harvell CD Princeton, New Jersey: Princeton University Press; 1999: I77-202.

37. Shafer TH, McCartney MA, Faircloth LM: Identifying exoskeleton proteins in the blue crab from an expressed sequence tag (EST) library. Integr Comp Biol 2006, 46:978-990.

38. Ogoh K, Ohmiya Y: Complete mitochondrial DNA sequence of the sea-firefly, Vargula hilgendorfii (Crustacea, Ostracoda) with duplicate control regions. Gene 2004, 327: | 3 |- 139.

39. Crosby MA, Goodman JL, Strelets VB, Zhang P, Gelbart WM: FlyBase: genomes by the dozen. Nucleic Acids Res 2007, 35:D486-D49I.

40. Adams MD, Celniker SE, Holt RA, Evans CA, Gocayne JD, Amanatides PG, Scherer SE, Li PW, Hoskins RA, Galle RF, et al.: The genome sequence of Drosophila melanogaster. Science 2000 , 287:2185-2195.

4l. Nardi F, Spinsanti G, Boore JL, Carapelli A, Dallai R, Frati F: Hexapod origins: monophyletic or paraphyletic? Science 2003, 299:| $887-1889$.
42. Giribet G, Edgecombe GD, Wheeler WC: Arthropod phylogeny based on eight molecular loci and morphology. Nature 2001 , 4|3:|57-|6I.

43. Pisani D, Poling LL, Lyons-Weiler M, Hedges SB: The colonization of land by animals: molecular phylogeny and divergence times among arthropods. BMC Biol 2004, 2: I.

44. Davis GK, D'Alessio JA, Patel NH: Pax3/7 genes reveal conservation and divergence in the arthropod segmentation hierarchy. Dev Biol 2005, 285: |69-184.

45. Colbourne JK, Eads BD, Shaw J, Bohuski E, Bauer DJ, Andrews J: Sampling Daphnia's expressed genes: preservation, expansion and invention of crustacean genes with reference to insect genomes. BMC Genomics 2007, 8:217.

46. Waridel P, Frank A, Thomas H, Surendranath $V$, Sunyaev S, Pevzner $P$, Shevchenko $A$ : Sequence similarity-driven proteomics in organisms with unknown genomes by LC-MS/MS and automated de novo sequencing. Proteomics 2007, 7:2318-2329.

47. Laforsch C, Ngwa W, Grill W, Tollrian R: An acoustic microscopy technique reveals hidden morphological defenses in Daphnia. Proc Natl Acad Sci USA 2004, I 0 I: I59| I- I59|4.

48. Jeschke JM, Tollrian R: Density-dependent effects of prey defences. Oecologia 2000, I 23:39|-396.
Publish with BioMed Central and every scientist can read your work free of charge

"BioMed Central will be the most significant development for disseminating the results of biomedical research in our lifetime. "

Sir Paul Nurse, Cancer Research UK

Your research papers will be:

- available free of charge to the entire biomedical community

- peer reviewed and published immediately upon acceptance

- cited in PubMed and archived on PubMed Central

- yours - you keep the copyright 